\title{
Solving Stefan's linear problem for drying cylindrical timber under quasi-averaged formulation
}

\author{
Gayvas B. I. ${ }^{1}$, Dmytruk V. A. ${ }^{2,1}$, Semerak M. M. ${ }^{2}$, Rymar T. I. ${ }^{2}$ \\ ${ }^{1}$ Centre of Mathematical Modelling, \\ IAPMM of National Academy of Sciences of Ukraine, \\ 15 D. Dudayev Str., 79005, Lviv, Ukraine \\ ${ }^{2}$ Lviv Polytechnic National University, \\ 12 S. Bandera Str., 79013, Lviv, Ukraine
}

(Received 16 December 2020; Revised 19 March 2021; Accepted 26 March 2021)

\begin{abstract}
The plain problem of drying of a cylindrical timber beam in the average statement is considered. The thermal diffusivity coefficients are expressed in terms of the porosity of the timber, the density of the components of vapour, air, and timber skeleton. The problem of mutual phase distribution during drying of timber has been solved using the energy balance equation. The indicators of the drying process of the material depend on the correct choice and observance of the parameters of the drying medium.
\end{abstract}

Keywords: porous timber, quasi-homogeneous approximation, integral transformation, phase transition, cylindrical function.

2010 MSC: 80A22, 33C10, 44A20, 30E10

DOI: $10.23939 / \mathrm{mmc} 2021.02 .150$

\section{Introduction}

Wood has a low density and thermal conductivity and belongs to the colloidal capillary-porous materials. The drying process of most colloidal materials is long [1,2] and varies [3]. The material is heated by convective energy transfer through the outer surfaces of the material in the presence of thermal gradients [4]. Wood drying involves taking into account the heat and mass exchange between the wood surface and humidified air and the internal heat and moisture exchange in the material [5-7]. For simulation of mathematical models of heat and mass transfer with phase transitions, an approach by means of methods with the phase boundary detection can be used [7]. For another approach, end-to-end calculation methods are used, for instance, using the generalized formulation of the classical Stefan problem [8]. To model systems characterized by "memory" effects, structural heterogeneity, spatial non-locality, deterministic chaos, and self-organization, the non-integer integro differentiation can be used $[9,10]$. To simulate mathematical models taking into account the eridarity and self-organization of the material, the finite-difference approximation can be used [11]. To simplify the model of heat and mass exchange, it can be assumed that the gas phase is water vapor, which is an ideal gas [8]. The task of choosing the optimal parameters of wood drying, at which the internal stresses in the dried material would be minimal, is urgent [9].

In stationary modes, the relationship between temperature and humidity gradients is determined by the formula

$$
\frac{\partial U}{\partial r}+\frac{\beta}{a} U=\frac{\delta \partial T}{\partial r}-\frac{\beta}{a} U_{p}
$$

where $\delta$ is the thermogradient coefficient; $\beta$ is the mass transfer coefficient; $a$ is the thermal diffusivity coefficient. In this dependence, the rate of moisture transfer is affected by the rate of heat transfer and by the equilibrium moisture content $U_{p}$ [5]. The relationship between the distribution of moisture content and temperature fields depends on the geometric dimensions of the timber material in length and radius. Since the length of the beam of material is much larger than the cross-sectional size and 
the coefficient of moisture conductivity is much larger along the fibers than this coefficient across the fibers and due to the great complexity of the structure of timber material, consider the plane average problem of heat conduction.

When the hot air of the drying agent contacts with the moisture of the dried material, the moisture particles disintegrate and multiply, turning into steam and rarefied moisture particles, the number of which increases [5]. Thus there is a multiplying of particles of a two-phase zone. At the same time there occurs a gradual deepening of the front of moisture evaporation. Heat is supplied to the evaporation front by heat conduction from the drying agent across the dried layer of material. Excess pressure is formed in the front zone, under the action of which the vapor is filtered to the outer surface. The total rate of moisture removal depends on the thermal and filtration resistance. The vapor pressure and the temperature at the front are related as parameters of saturated vapor. The slow movement of the front into depth allows us to consider the fields of temperature and excess pressure in the dried material to be quasi-stationary. The drying process with a variable phase transition boundary is described by the equation [8]

$$
\frac{\partial T}{\partial \tau}+\gamma^{2} T=a^{2} B_{\alpha}[T, r], \quad \gamma^{2}=\frac{\gamma_{1}^{2}}{C \rho}, \quad \alpha>0
$$

where

$$
a^{2}=\frac{\lambda}{\left[\Pi\left(C_{v} \rho_{v}+C_{a} \rho_{a}\right)+(1-\Pi) C_{s} \rho_{s}\right]}
$$

is averaged thermal diffusivity coefficient.

Solve Eq. (1) under the initial condition

$$
\left.T(\tau, r)\right|_{\tau=0}=g(r), \quad r \in(0, R)
$$

and under the boundary conditions on $r=0$ and $r=R$, which express heat exchange in the cylinder and between the surface of the cylinder and the drying agent:

$$
\lim _{r \rightarrow 0} \frac{\partial}{\partial r}\left(r^{\alpha} T\right)=0, \quad \lim _{r \rightarrow R}\left(\alpha_{11}^{1} \frac{\partial}{\partial r}+\beta_{11}^{1}\right) T=T_{a}(\tau)
$$

The process of penetration of hot air, the rate of which is proportional to the concentration, leads to the problem of phase transition if $\gamma^{2}<0$ (diffusion with decay), the indices of a series

$$
T(M, t)=\sum_{n=1}^{\infty} T_{n} e^{\left(\gamma^{2}-a^{2} \lambda\right) t} v_{n}(M)
$$

obtained by expansion in terms of eigenvalues functions $v_{n}(M)$, are less than the indices of a series if not to take into account changes in temperature over time without a phase transition. In the case $\gamma^{2}>0$ (penetration with multiplication), if at least one of the indices $\left(\gamma^{2}-a^{2} \lambda\right)>0$, then there is an increase by the exponential law. The value $\gamma^{2}$ is a characteristics of the material (multiplication factor), $\lambda$ significantly depends on the shape and size of the area (pores). If $\lambda=\frac{\gamma^{2}}{a^{2}}$, then the area where the phase transition occurs has critical dimensions. For a plane problem, the smallest value of $\lambda$ corresponds to the eigenfunction, which has radial symmetry and is equal to $\lambda_{1}=\frac{\mu_{1}^{(0)}}{R}, \mu_{1}^{(0)}=2.4048$ [5].

For the critical diameter, the formula $d_{k p}=\frac{2 \mu_{1}^{(0)} a}{\gamma}=\frac{4.80 a}{\gamma}$ is obtained [5].

When solving the problem of drying objects with a capillary-porous structure, in particular wood, in order not to consider the porous body in all its complexity, it is described in terms of a quasihomogeneous medium with effective coefficients, which are chosen so that the solution of the problem in a homogeneous medium coincides with the solution in a porous medium. The influence of the porous structure is taken into account by introducing the effective binary interaction coefficients into the Stefan-Maxwell equation. The problem of mutual phase distribution is solved using the principle 
of local phase equilibrium. We consider that the averaged properties of the material, namely: heat capacity $C$, density $\rho$, and thermal conductivity coefficients $\lambda$ are functions of porosity of material, densities and heat capacities of body components.

\section{Problem statement}

Consider the problem of drying a wet timber beam of cylindrical cross section in a drying plant. In solving this problem, we neglect the discrete structure of the material at the molecular level. We come to the equation of heat conduction

$$
\frac{\partial T}{\partial \tau}(\rho, \tau)=a \Delta T+\gamma^{2} T, \quad, \gamma^{2}>0
$$

Here, $a$ is the thermal diffusivity coefficient, $\gamma$ is a variable equivalent to the presence of sources of diffusing substance in the pores, $T$ is the body temperature. The higher the temperature is, the higher the rate of drying. The temperature in the drying chamber is the temperature in the vapor-gas mixture, which is determined by a dry bulb thermometer. The temperature determined by a wet bulb thermometer is the temperature at the boundary of the phase transition, which moves inside the material. The difference between the readings of dry and wet bulb thermometers is used to determine the relative humidity. For successful air drying, a continuous flow of air throughout the beam must be ensured. In the drying chambers, unsaturated air is used as a drying agent. Successful operation of drying chambers is achieved by regulating the temperature and humidity at the right time [7-9].

The volume of the dried area is a function of time. In this case, the body to be dried is a cylindrical beam, the outer surface of which $F(r, \tau)=0$ is described by the equation

$$
F(r, \tau)=r-1=0, \quad \tau=0 .
$$

At the time moment $\tau=0$, the temperature $T_{0}(\tau)$ is applied to the outer surface of the cylinder and from this time the drying process begins, and at the interface of the phase transition the curve of separation of dry and wet zones is the temperature $T_{c}(\tau)$ curve.

In the process of drying, this curve moves, forming a closed curve $F_{k}(r, \tau)=0$, which is an isotherm $T=T_{c}$. In the zone where the drying has already taken place, the temperature is described by the equation of heat conduction and by boundary conditions, these boundary conditions can be written as:

on the outer contour of the cylinder $F_{k}(r, \tau)=0$

$$
T=T_{c},
$$

and the following initial conditions:

$$
T=T_{0}, \quad F_{0}=F_{k}, \quad \tau=0 .
$$

Let $V\left(F_{k}, F_{0}\right)$ be the volume of the dried area at the time $t$ per unit length of the beam in the direction of the axis $O z$. Then, over a period of time $\Delta t$, the volume will increase by $\Delta V\left(F_{k}, F_{0}\right)$, and the amount of heat spent is

$$
\Delta Q=\rho_{k} c_{k}\left(T-T_{c}\right) \Delta V\left(F_{k}, F_{0}\right) .
$$

Determine this amount of heat through the flow on the surface $F_{k}(r, \tau)=0[8]$ :

$$
\Delta Q=-\lambda_{k} \int_{F_{k l}=0} \frac{\partial T}{\partial n} d s \Delta t .
$$

Passing in Eq. (8) to the limit at $\Delta t \rightarrow 0$, given (7), we obtain

$$
\lambda_{k} \int_{F_{k l}=0} \frac{\partial T}{\partial n} d s=-\rho_{k} c_{k}\left(T-T_{c}\right) \frac{d V\left(F_{k}, F_{0}\right)}{d t}
$$


where $F_{0 l}, F_{k l}$ are contours of cross-sections of surfaces $F_{0}=0, F_{k}=0$, respectively.

$$
V\left(F_{k}, F_{0}\right)=\iint_{F_{k}=0}^{F_{0}=0} d s .
$$

If we pass to the variables

$$
\eta=\frac{T-T_{c}}{T_{0}-T_{c}}, \quad \beta=\frac{\rho_{k} c_{k} a}{\lambda_{k}}, \quad \vartheta=\frac{V}{R^{2}}, \quad l=\frac{s}{R}, \quad \sigma=\frac{s}{R^{2}},
$$

then dimensionless coefficients will satisfy the equation of heat conduction and the boundary conditions (5), (6):

at $F_{0}=0$

$$
\eta=1
$$

at $F_{k}=0$

$$
\begin{gathered}
\eta=0 ; \\
\eta=1, \quad \tau=0 .
\end{gathered}
$$

Consider the equation of the Stefan's boundary change:

$$
\begin{gathered}
\beta \eta \frac{d \vartheta}{d \tau}=-\frac{\partial T}{\partial n} d l, \\
\vartheta\left(F_{0}, F_{k}\right)=\iint_{F_{k}=0}^{F_{0}=0} d \sigma .
\end{gathered}
$$

Note that at the beginning of the drying process

$$
F_{k}(x, y, \tau)=F_{0}(x, y), \quad \varepsilon^{*}(t)=0 .
$$

Over a short period of time, the contour of the boundary of the dried and wet zones will be as follows:

$$
F_{k}(x, y, t)-F_{0}\left(x_{1}, y_{1}\right)=\varepsilon^{*}(t),
$$

where $\varepsilon^{*}(t)$ is the thickness of the layer of the dried area (17). From the symmetry of the problem it follows that the contours $F_{0}, F_{k}$ are concentric circles, the equations of which in a dimensionless polar system are

$$
F_{0}=r-1=0, \quad F_{k}(t)=r-1+\varepsilon(t)=0, \quad \varepsilon=\frac{\varepsilon^{*}}{R}
$$

With this, $\varepsilon(\tau)=0$ for $\tau=0$.

From (18) it follows that at the time of complete drying of the beam

$$
\varepsilon^{*}(t)=R
$$

and, respectively,

$$
\varepsilon(\tau)=1
$$

Write the equation of heat balance for the area bounded by the contours $F_{0}, F_{k}(t)$. In integral form, this equation can be written as

$$
\iint_{F_{k}=0}^{F_{0}=0} \frac{\partial \eta}{\partial \tau} d \sigma=\int_{F_{0 l}} \frac{\partial \eta}{\partial n} d l-\int_{F_{k l}} \frac{\partial \eta}{\partial n} d l .
$$

If we take into account the boundary condition (14), we obtain:

$$
\int_{F_{k}=0}^{F_{0}=0} \frac{\partial \eta}{\partial n} d \sigma=\int_{F_{0 k}} \frac{\partial \eta}{\partial n} d l+\beta \eta \frac{\partial \eta}{\partial \tau} .
$$


Equation (20) is the main one, which takes into account the factor of the moving boundary.

Introduce the function $\eta^{*}(r, \tau)$ so that it satisfies the initial and boundary conditions (13). This function will establish the relationship between the relative saturation and temperature in the cross section in time.

$$
\eta^{*}(r, \tau)=\frac{r-1+\varepsilon(\tau)}{\varepsilon(\tau)} .
$$

Let us take $\eta^{*}(r, \tau)$ as an approximate solution, which at a certain value $\varepsilon(\tau)$ must satisfy Eq. (19). There is a relationship between it and $\varepsilon$

$$
\begin{gathered}
\frac{\partial \eta^{*}}{\partial \tau}=(1-r) \frac{1}{\varepsilon^{2}} \frac{d \varepsilon}{d t}, \quad \frac{\partial \eta^{*}}{\partial n}=\frac{\partial \eta^{*}}{\partial r}=\frac{1}{\varepsilon} \\
\int_{F_{0 l}} \frac{\partial \eta *}{\partial n} d l=\frac{2 \pi}{\varepsilon}, \quad \iint_{F_{k}=0}^{F_{0}=0} \frac{\partial \eta *}{\partial n} d \sigma=\int_{0}^{2 \pi} d \varphi \int_{1-\varepsilon}^{1} \frac{1-r}{\varepsilon^{2}} \frac{d \varepsilon}{d \tau} r d r=\frac{\pi}{3}(3-2 \eta) \frac{d \varepsilon}{d \tau} .
\end{gathered}
$$

From Eq. (20) we obtain

or

$$
\varepsilon^{2}+\varepsilon \frac{1-2 \beta \eta^{*}}{2\left(3 \beta \eta^{*}-1\right)} \frac{d \varepsilon}{d \tau}=\frac{3 \beta \eta^{*}}{3 \beta \eta^{*}-1}
$$

$$
\begin{gathered}
d \tau=\frac{1}{B}\left(\varepsilon^{2}+A \varepsilon\right) d \varepsilon, \quad \tau(0)=0, \\
B=\frac{3 \beta \eta^{*}}{3 \beta \eta^{*}-1}, \quad A=\frac{1-2 \beta \eta^{*}}{2\left(3 \beta \eta^{*}-1\right)} .
\end{gathered}
$$

The solution of Eq. (24) is

$$
\tau=\frac{1}{B}\left(\frac{\varepsilon^{3}}{3}+A \frac{\varepsilon^{2}}{2}\right) .
$$

From Eqs. (14) and (26), taking into account Eqs. (15) and (18), we obtain the equation that describes the change in the unit of length of the volume of the dried zone over time: $V_{d}=\pi R^{2}\left[1-\varepsilon^{2}(\tau)\right]$ and, thus, now we are able to calculate the relative humidity of the timber beam during drying $W=\frac{V-V_{d}}{V}$. Simple formulae for approximation of the experimental data allow us to calculate the total duration of the drying process from the initial to the final moisture content of the material.

\section{Numerical experiment}

Based on the obtained solutions, the numerical simulation of drying of samples of timber circular beams of pine, spruce, and birch of the same size has been carried out. The material after preliminary natural drying had been brought to $15 \%$ humidity. The following basic parameters of the problem have been accepted: the ambient temperature $T_{c}=313 \mathrm{~K}$; the velocity of the drying agent $v=2 \mathrm{~m} / \mathrm{s}$; the saturated vapor density $\rho_{n}=0.013188 \mathrm{~kg} / \mathrm{m}^{3}$; the air density $\rho_{a 0}=1.29 \mathrm{~kg} / \mathrm{m}^{3}$. Physical parameters of timber: the radius of a circular beam $R=0.07 \mathrm{~m}$; wood density: spruce $450 \mathrm{~kg} / \mathrm{m}^{3}$, pine $500 \mathrm{~kg} / \mathrm{m}^{3}$, birch $750 \mathrm{~kg} / \mathrm{m}^{3}$; the porosity: pine $\Pi=0.672$, spruce $\Pi=0.654$, birch $\Pi=0.591$. Thermal parameters of wood: the initial temperature $T_{0}=293 \mathrm{~K}$, the thermal conductivity coefficient at humidity of $15 \%$ across fibers: spruce $\lambda=0.11 \mathrm{~W} /(\mathrm{mK})$, pine $\lambda=0.14 \mathrm{~W} /(\mathrm{mK})$, birch $\lambda=0.14 \mathrm{~W} /(\mathrm{mK})$.

Fig. 1 shows the changes in the thickness of the layer of the dried area $\varepsilon$ in time of drying $\tau$.

From the graph, we can see a clear dependence of drying time on the physicochemical properties of timber, namely: wood with higher porosity and lower density dries faster (Fig. 1, curves 1, 2) than the denser wood with lower porosity (Fig. 1, curve 3). Note that wood species that have approximately similar thermal conductivity index were studied.

In Fig. 2, the distributions of relative humidity of wood in time are presented. 


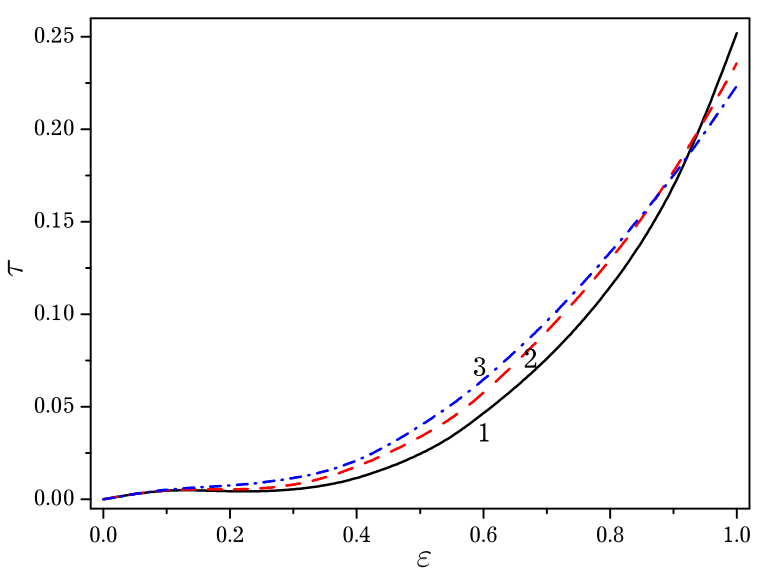

Fig. 1. The dependence of thickness of layer of the dried area on time of drying (curves 1-3 correspond to sort of materials: spruce, pine, birch, respectively).

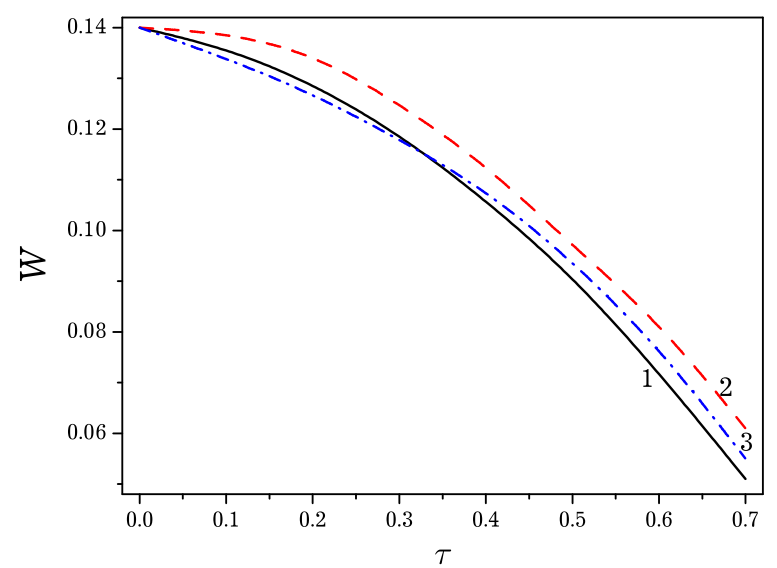

Fig. 2. Change in relative humidity of beam skeleton in time (curves 1-3 correspond to materials: spruce, pine, birch, respectively).

We can observe that the samples with greater porosity and lower density lose moisture faster (Fig. 2, curves 1,2 ), the moisture from wood with less porosity is removed more slowly (Fig. 2, curve 3).

The obtained results correspond to the experimental data given in the literature.

\section{Conclusions}

It has been established that in the process of drying timber materials, the movable surface of the phase transition, which separates the dried and wet zones, depends on the properties of the material and temperature, which is a function of coordinates and time. The formulated problem of mutual phase distribution during drying of timber has been solved taking into account given properties of the material, namely: heat capacity, density, thermal diffusivity coefficients, which are expressed as functions of the porosity of the material, densities, and heat capacities of the components. The relationship is established between the drying time and the average parameters of porous cylindrical timber, in particular the relative saturation of moisture, the thermal conductivity of timber, which take into account the factor of movement of the mobile boundary of the dried zone.

[1] Gnativ Z. Ya., Ivashchuk O. S., Hrynchuk Yu. M., Reutskyi V. V., Koval I. Z., Vashkurak Yu. Z. Modeling of internal diffusion mass transfer during filtration drying of capillary-porous material. Mathematical Modeling and Computing. 7 (1), 22-28 (2020).

[2] Kaletnik G., Tsurkan O., Rymar T., Stanislavchuk O. Determination of the kinetics of the process of pumpkin seeds vibrational convective drying. Eastern-European Journal of Enterprise Technologies. 1 (8), 50-57 (2020).

[3] Hayvas B., Dmytruk V., Torskyy A., Dmytruk A. On methods of mathematical modelling of drying dispersed materials. Mathematical Modeling and Computing. 4 (2), 139-147 (2017).

[4] Ugolev B., Skuratov N. Modeling the wood drying process. Collection of scientific works of MLTI. 247, 133-41 (1992).

[5] Shubin G. Drying and heat treatment of wood. Moscow, Forest Industry (1990), (in Russian).

[6] Tikhonov A., Samarskii A. Equations of mathematical physics. Moscow, Nauka (1972), (in Russian).

[7] Markovych B. Investigation of effective potential of electron-ion interaction in semibounded metal. Mathematical Modeling and Computing. 5 (2), 184-192 (2018).

[8] Gupta S. C. The Classical Stefan Problem. 2nd edition. Elsevier, USA, 750 (2017). 
[9] Kostrobij P., Markovych B., Viznovych B., Zelinska I., Tokarchuk M. Generalized Cattaneo-Maxwell diffusion equation with fractional derivatives. Dispersion relations. Mathematical Modeling and Computing. 6(1), 58-68 (2019).

[10] Kostrobij P. P., Markovych B. M., Ryzha I. A., TokarchukM. V. Generalized kinetic equation with spatiotemporal nonlocality. Mathematical Modeling and Computing. 6(2), 289-296 (2019).

[11] Sokolovskyy Y., Levkovych M., Sokolovskyy I. The study of heat transfer and stress-strain state of a material, taking into account its fractal structure. Mathematical Modeling and Computing. 7(2), 400-409 (2020).

[12] Carslaw H. S., Jaeger J. C. Conduction of Heat in Solids. Oxford University, London (1959).

[13] Lenyuk M., Mikhalevska G. Integral transformations of the Kontorovich-Lebedev type. Chernivtsi Prut. (2002), (in Ukrainian).

[14] Fedotkin I. M., Burlyai I. Yu., Ryumshin N. A. Mathematical modeling of technological processes. Kiev, Technics (2002), (in Russian).

\title{
Побудова розв'язку лінійної задачі Стефана для осушення циліндричного бруса в квазіусередненій постановці
}

\author{
Гайвась Б. I. ${ }^{1}$, Дмитрук В. А. ${ }^{2,1}$, Семерак М. M. ${ }^{2}$, Римар T. I. ${ }^{2}$ \\ ${ }^{1}$ Центр математичного моделювання \\ ІППММ Національної академї наук України, \\ вул. Дж. Дудаєва, 15, 79005, Лъвів, Украӥна \\ ${ }^{2}$ Національний університет "Львівсъка політехніка", \\ вул. С. Бандери, 12, 79013, Львів, Україна
}

\begin{abstract}
Розглянуто плоску задачу сушіння циліндричного бруса в усередненій постановці. Коефіцієнти температуропровідності виражено через пористість матеріалу деревини, густину компонентів пари, повітря та скелету. Задача про взаємний розподіл фаз під час сушіння деревини розв'язується з використанням рівняння балансу енергії. Від правильного вибору та дотримання параметрів сушильного середовища залежать показники процесу сушіння матеріалу.
\end{abstract}

Ключові слова: пориста деревина, квазігомогенне наближення, інтегральне перетворення, фазовий перехід, циліндрична функція. 